Military Technical College Kobry El-Kobbah, Cairo, Egypt

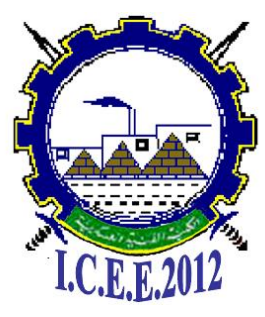

$6^{\text {th }}$ International Conference on

Chemical \& Environmental Engineering

29 - 31 May, 2012

CEEA-3

\title{
UTILIZATION OF ALUMINUM DROSS TAILINGS TO PRODUCE A COAGULANT
}

\author{
M. Zakaria Abdel Wahhab*
}

\begin{abstract}
Highly pure aluminum sulphate is an important chemical from the industrial point of view, especially for paper makers. It is also used for water treatments, dyeing of cloth, fire proofing fabrics, leather tanning and for cellulosic insulations. Dross is an industrial waste from aluminum production factories and is of wide varieties, being a problematic issue for aluminum producing factories, such as the Egyptian Aluminum company at Nag Hammadi which produces hudge amounts daily of such wastes needing either marketing, landfilling or processing to useful products . The present investigation exposes one of the processing ideas of changing the aluminum content of such waste either to impure aluminum sulphate solution, pure aluminum sulphate solution or aluminum sulphate in the solid form, using simple treatments at low temperatures so as to increase benefits and decrease costs of transformation. Laboratory studies proved the possibility of such transformations at temperatures ranging from $70^{\circ} \mathrm{C}$ to $100^{\circ} \mathrm{C}$, using sulphuric acid. These results had been scaled-up for an engineering scope by the design of a semi-pilot scale sediment where the laboratory sedimentation results of the obtained aluminum sulphate had been tried .

Results of the present investigation represent a step for environmental friendship by processing the daily dross waste at the Nag Hammadi "Egyptalum company", by increasing the income from selling such a waste to other purchasers ; whereby "the waste " dross will become an aluminum " by-product" .
\end{abstract}

Key Words: Aluminum dross, environmental impact, tailings, coagulant, sedimentation.

* Dept. of Chem. Engineering, Fac. Of engineering, Minia University, Minia, Egypt

E-mail: Profzakaria1@ Yahoo.com

Phone: (Office) 086/9247891, (Home): 086/2316857

Fax (Faculty): 086/234667 


\section{$\underline{\text { Introduction }}$}

The aluminum dross tailing, ADT is a "waste " or by-product " of melting aluminum metal. It is a mixture of aluminum metal and aluminum oxide with minor amounts of other constituents. In Egypt, the "Egyptalum " company at Nag Hammadi considers the produced dross as a waste causing serious pollution problems for the environment; it is discarded, thus , in landfills or sold at very low prices for private users. The aluminum dross tailings represents $15 \%$ of the total annual aluminum wastes of Egyptulum which may attain about 15000 tons, [1].

While there are many subcategories of aluminum by-products, there are three main forms of drosses, these are: the white dross, the black dross and the salt cake [2]. The white dross is of higher metal aluminum content and it is produced from primary and secondary aluminum smelters, whereas black dross has a lower metal content and is generated during aluminum recycling. White dross may contain from 15 to $70 \%$ recoverable metallic aluminum and it comprises a fine powder from skimming the molten aluminum [3]. Black dross typically contains a mixture of aluminum oxides and slag, with recoverable aluminum content ranging between 12 to $18 \%$, and much higher salt content (higher than $40 \%$ ), than white dross [3].

The international production of white dross by the year 2002 was reported to be about four million tons, while the black dross amounted to more than a million ton. The aluminum oxides produced from aluminum dross recycling could be utilized together with other alternative materials to produce premixes for clinker production in the cement industry. This can be achieved by using alternative materials that contribute essential components in the cement's recipe, namely lime, silica, alumina and iron oxide [4].

The objective of the present investigation is the production of alums from aluminum dross tailings as a means to reduce its bad effect on the environment of Nag Hammadi or elsewhere the aluminum metal is produced. Also, these produced alums, which mainly consists of aluminum sulphate, can be purified to obtain the pure sulphate which is commertially known as "paper makers alum " or " filter alum" [5,6]. These purified species are used industrially for water treatment $[6,7]$, sizing of paper [8] , dyeing, fire proofing fabrics , tanning and cellulosic insulations $[6,9]$.

\section{Materials :}

1- The material used in this investigation is the aluminum dross tailing (ADT) itself; two types of which are known to be produced, namely the white and the black one. The dross used in the present investigation is of the white type; its impurities metal contents are as follows (weight percentages ):

\begin{tabular}{|c|c|c|}
\hline Mg 1.84 & $\mathrm{Zn} 0.32$ & $\mathrm{Na} \quad 2.90$ \\
\hline Mn 0.23 & $\mathrm{Cu} 0.01$ & As 0.002 \\
\hline $\begin{array}{ll}\mathrm{Si} & 0.40\end{array}$ & $\begin{array}{ll}\mathrm{V} & 0.02\end{array}$ & $\begin{array}{ll}\mathrm{Pb} & 0.003\end{array}$ \\
\hline $\mathrm{Fe} \quad 0.57$ & & \\
\hline
\end{tabular}

Chemical analysis showed a percentage of aluminum of $51.53 \%$ by weight . The nitrogen content of the sample was evaluated as $6.48 \%$ by weight, while the chlorides and carbon were $4.4 \%$ and $1.8 \%$ by weight respectively, as analysed . 
The fine sizes of the dross samples were used for the present investigation (sizes less than $0.08 \mathrm{~mm}$ diameter - 80 microns).

2- Aluminum sulfate in well-a pure solid form (A.R) ( specific gravity 1.33) was used as a known coagulant.

3- Commertial alum particles of chemical composition $\mathrm{Al}_{2}\left(\mathrm{SO}_{4}\right)_{3} \cdot 14 \mathrm{H}_{2} \mathrm{O}$ were also used for preparing alum solutions of different concentrations as another proof for the extent of availability of the produced solutions from the dross material ( specific gravity 1.67) .

4- Sulfuric acid $98 \%$ A.R. (specific gravity 1.84), was used for preparing acid solutions .

5- Potassium hydroxide (A.R), (specific gravity 2.04) was used for neutralization of excess acid .

6- Calcium carbonate, $\mathrm{C}_{\mathrm{a}} \mathrm{CO}_{3}$, ( sp. gr 1.98), of mean particle size 63 microns.

7- Clay, of natural origin from the Minia governorate, El-Sheikh Fadl location , (sp.gr.2.61) and mean particle size 73 microns.

\section{$\underline{\text { Apparatus }}$}

Since the main objective of this study, as mentioned, is to test the feasibility of the ADT for sedimentation of fines from suspensions, it was decided to proceed first on a laboratory scale so as to notice the changes and relative variabilities of the process .

Plastic measuring cylinders having the same physical features and dimensions were used for sedimentation tests. They were of two liters capacity and $100 \mathrm{~mm}$ in diameter. Controlled drying ovens were used to dry the filtered caba. The optimum accepted conditions were tested on a semi-pilot scale in batch conditions of operations. The solids used as suspensions were of sizes below 100 microns so as to eliminate the wall effect of the vessels used [10].

\section{Methodolgy procedure}

To simplify the study procedure, it was decided to follow the following steps:

1- To purify the ADT from gangue elements

2- To prepare aluminum sulfate from the purified solid of the first step

3- To leach the prepared aluminum sulfate in the second step

4- To examine the feasibility of the leachate as fines dispersed from suspensions, on a laboratory scale

5- To verify the laboratory scale results on a semi-pilot scale.

\section{$\underline{\text { I- Purification of the ADT sample from gangue elements }}$}

A study of the metal content of the ADT sample showed the presence of metals in the form of compounds confirmed by the atomic absorption technique, such as $\mathrm{AlN}, \mathrm{Al}_{4} \mathrm{C}_{3}, \mathrm{CuO}, \mathrm{Fe}_{2} \mathrm{O}_{3}$, $\mathrm{M}_{\mathrm{n}} \mathrm{O}$ and others for the metals nominated in the material section. The aluminum content was confirmed by the chemical EDTA titration as well as by atomic absorption.

Dilute sulfuric acid was used to leach the major impurities (gangue) present in the ADT sample . Preliminary experiments showed the best concentration of acid to be used to attain the max possible purification condition of the sample. 
It was noticed that some aluminum present in the sample was leached with the impurities, whose percentage increased by increasing the concentration of the acid. The best dilution of acid used for leaching was found to be $5 \%$; corresponding to the least amount of aluminum leached.

The time of leaching was 6 hours, at $100^{\circ} \mathrm{C}$ temperature with continuous agitation at speeds ranging from 200 to $300 \mathrm{rpm}$. The ratio of the acid to the ADT sample by weight was taken as 150 to 100 . The volume of acid was thus calculated to be equivalent to $150 \mathrm{~g}$ acid to each $100 \mathrm{~g}$ ADT.

It was also found that the aluminum sulfate leached with impurities was in the form of the double sulfate ammonium aluminum sulfate dodecahydrate [ $\left(\mathrm{NH}_{4}\right) \mathrm{Al}\left(\mathrm{SO}_{4}\right)_{2} \quad 12 \mathrm{H}_{2} \mathrm{O}$ ] as confirmed by x-ray diffraction, which thus can be obtained in a solid form or used as it is in the liquid soluble form[4]. Figures 1,2,3 and 4 give a summary of the preliminary studies carried out in order to establish the best conditions for removing impurities without increasing losses in the aluminum content of the original ADT sample.

It is of worth noting that at the end of the leaching time, the suspension was subjected to filtration, where the solid was further washed with hot water, then the filtrate and the dried solid were subjected to chemical or instrumental analysis.

\section{$\underline{\text { II- Aluminum sulfate preparation from purified ADT }}$}

Using the dry solid obtained from the preceding step, it was clear that the transformation of the aluminum compounds to the aluminum sulfate can be done by using the proper amount and concentration of sulfuric acid according to the equation :

$$
\mathrm{Al}_{2} \mathrm{O}_{3}+3 \mathrm{H}_{2} \mathrm{SO}_{4}-------------------\mathrm{Al}_{2}\left(\mathrm{SO}_{4}\right)_{3}+\mathrm{H}_{2} \mathrm{O}
$$

Analytical references state the exact procedure and amount acid of reagents required, according the stiochiometric relations and the excess acid required. The temperatures accepted for such transformation lie between 70 and $200^{\circ} \mathrm{C}$ for a time of one hour. Different concentrations of the acid were tried between $30 \%$ and $98 \%$ sulfuric acid in order to attain the best concentration giving maximum transformation. It was found that acid concentrations between $30 \%$ and $50 \%$ gave conversions not exceeding $95 \%$ of the total aluminum content of the sample tested, as shown in figure (5). An acid/dross ration of 1.4 was found to be of a critical value which gives the maximum transformation, below or more than which the reaction efficiency decreases . In addition, the acid ratio of (1.4) was found to be the best ratio above which (and up till a ratio of 2.2) there was no additional increase in transformation, as shown in figure (6) and figure (7).

\section{III- Leaching of the formed aluminum sulfate :}

The aluminum sulfate formed in the preceding step had been separated from the unreacted portion of the sample by filtration. To make filtration easier, the reaction mass was diduted by hot distilled water and mixed thoroughly. 
The solid residue is washed by hot water several times to ensure the depleting of the solid from all its content of the aluminum sulfate, which was found by analysis to be more than 85 $\%$ of the original mass after reaction completion. The filtrate from that filtration process and its content of washings contain the whole required aluminum sulfate from the ADT sample, which constitutes the main solution to be used for the sedimentation and settling operations mentioned in the following items of that investigation.

Many investigators studies the kinetics of this transformation reaction [11], they found that their data obtained were best represented by a simple rate equation of the form :

$$
\frac{d c}{d t}=k\left(\frac{1}{t}\right)^{n}
$$

Where,

$$
\begin{aligned}
& \mathrm{k}=\text { reaction rate constant }\left(\mathrm{h}^{-1}\right) \\
& \mathrm{n}=\text { order of the reaction } \\
& \mathrm{c}=\text { concentration of sulfuric acid (weight \%) } \\
& \text { and } \quad \mathrm{t}=\text { time },(\mathrm{h})
\end{aligned}
$$

Fitting of the data obtained using the standard statistical methods showed that the correlation coeffient ranged from 0.989 to 0.995 . These authors also tabulated values for $(\mathrm{k})$ and $(\mathrm{n})$ of the reaction for different acid concentrations for both the leaching and the extraction processes. The $(\mathrm{k})$ values $\left(\mathrm{h}^{-1}\right)$ for leaching were of the order of 1.08 to 3.8 and for extraction of 2.15 to 2.26 , while those values of (n) were for leaching between $(0.7$ and 0.9$)$ and for extraction between (0.74 and 0.75).

\section{$\underline{\text { IV. Feasibility of the obtained aluminum sulfate as a coagulant }}$}

\section{A) procedure :}

To study the feasibility of the obtained " prepared aluminum dross tailing (PADT) solution, it was important to proceed as follows :

1- To complete the prepared solution obtained to a fixed volume relative to the highest expected volume obtained from all experiments, then to thoroughly mix the contents .

2- To titrate a sample of the mixed solution by an alkali to neutralize it using an indicator; then to neutralize the whole solution by adding the calculated amount of alkali required for neutralization of the whole solution in order to stop further transformations, if any . It is important here to ensure the complete neutralization .

3- To analyse for the content of the sulphate ion in a sample and to calculate the concentration of the whole solution of the sulfate ion.

4- The whole solution is preserved in coloured labeled bottles and kept in dark for future uses. 
5- To begin a sedimentation test, the testing cylinder is well cleaned; the required solid weight is carefully put in its bottom by using an elongated neck funnel whose elongated neck reaches very near to the cylinder bottom.

6- The required amount of the (PADT) is added through the funnel, and then the water is added through the funnel while raising it up during addition for a while, then completing its livel in cylinder to a pre-designed height which is the same for all experiments except those designed for testing the suspension height effect.

7- Using a glass rod, the contents of the cylinder are thoroughly mixed so as to have a homogeneous suspension of constant solid concentration allover the whole height and cross section of the cylinder, then to clean the rod using a washing bottle.

8- Using a stop watch, the time of the downward transfer of the suspended solid surface and the elevation of the sediment surface were recorded and tabulated.

9- The data are then compared for the different sedimentors used, which are : the analytical reagent aluminum sulfate $\left[\mathrm{Al}_{2}\left(\mathrm{SO}_{4}\right)_{3}\right]$, commercial alum $\left[\mathrm{Al}_{2}\left(\mathrm{SO}_{4}\right)_{3} \cdot 14 \mathrm{H}_{2} \mathrm{O}\right]$ and the prepared aluminum dross tailing solution [PADT, impure $\mathrm{Al}_{2}\left(\mathrm{SO}_{4}\right)_{2}$ ].

10-Different density and purity materials were used as suspended particles so as to differentiate between the settling behaviour of the PADT with respect to the behaviour of other sedimentors for different suspension qualities, in some experiments, concentrating on the use of clay only for the others.

\section{B) Discussion of the obtained results}

Figures 8,9 and 10 show the relation between the interface height $(\mathrm{H})$ and time for the solid fines at low concentrations by using different aluminum sulphate grades ; that were as mentioned before analytical reagent, commercial alum and the PADT obtained. The solids used were : clay, $\mathrm{CaCO}_{3}$, original dross and roasted dross.

It is clear that the obtained PADT can be considered as a good substitute for both other two reagents from an economic point of view, being obtained from an industrial effluent. Yet, in some cases shown, Fig.11, it may be considered even better. This may be due to the presence of some other aluminum ingredients in the original dross before treatment such as the aluminum nitride (AlN) and the aluminum carbide $\mathrm{Al}_{4} \mathrm{C}_{3}$ which may be transformed by the sulphuric acid either to the single sulphate or to the double sulphate $\left(\mathrm{NH}_{4}\right) \mathrm{Al}\left(\mathrm{SO}_{4}\right)_{2} \cdot 12 \mathrm{H}_{2} \mathrm{O}$ [11].

It is important to note here that the type of settling of particles is of the free type, being not hindered by the walls of the container or by the high packing of particles in the vessel. These both are due to the experimental design of using a ratio of the diameter of the vessel used to be hundred times higher ( or more) than the mean diameter of the particles sedimenting, i.e. $D_{\text {vessel }} / D_{\text {paricle }} \geq 100$; and also by using dilute suspensions (not more than $3 \%$ being actually 1-2 \% ). The concentration of the used PADT solution could be increased by mild evaporation techniques, at $80^{\circ} \mathrm{C}$ to obtain higher concentration of the sulphate ions as well as it could be diluted to decrease concentration. Higher concentrations of the PADT proved better settling action in quality and in a lower sedimentation time. From two to five percents PADT of the 
total suspension volume were found to be of accepted sedimentation results, these were judged by a percentage of particles sedimented with respect to their mass at the beginning of the experiment. These statements can be clarified from the figures 12 and 13 .

Since the used particles were smaller than 100 microns ( actually of mean particle size of the order of 0.63 micron ( as confirmed by size analysis on a Tyler screen series ) the particles have been assumed to be spherical, obeying thus Stoke's law. The particles will increase in velocity in the liquid medium under the action of the gravitational force until the accelerating force is exactly balanced by the resistance force [10]. A relation for the terminal falling velocity states that:

$$
\mathrm{U}_{\mathrm{o}}=\frac{g D^{2}\left(\rho_{S}-\rho\right)}{18 \mu}
$$

Where $\quad \mathrm{D}=$ mean particle size of solids $(\mathrm{m})$

$\rho_{\mathrm{s}}=$ density of solid $\left(\mathrm{kgm}^{-3}\right)$

$\rho=$ density of water $\left(\mathrm{kgm}^{-3}\right)$

$\mathrm{g}=$ acceleration of gravity $\left(\mathrm{ms}^{-2}\right)$

$\mu=$ viscosity of water (Pa.s)

$\mathrm{U}_{\mathrm{o}}=$ terminal settling velocity $\left(\mathrm{m} \mathrm{s}^{-1}\right)$

Applying this equation to the obtained results showed acceptable falling velocities of the particles in the range of 42 to $48 \mathrm{~mm} / \mathrm{s}$.

The effect of the suspension height on the rate of sedimentation was studied and the results obtained were in good similarity with those mentioned in literature [10] . Results proved that parallel curves were obtained, to the extent that any line connecting the origin with any point on a curve will have the same relative values of its portions from the origin, as shown in figure 14 , which means that, the original height of the suspension; had actually no effect on the sedimentation rate.

\section{V-Semi-pilot applications of the laboratory results}

To ensure the engineering feasibility of the laboratory tested results, a simplified semi-pilot batch plant was designed as shown in figure 15 . The settling vessel had a lower conical section, and the vessel was made of the transparent Perspex polymeric material so as to observe the interior transfer of the settling particles. The vessel total capacity was 1.2 tons, of diameter one meter in its circular upper section. Its movable cover is used for adding the solids and coagulants (manually).

The vessel was mounted on a metallic installation, which also carries a motor and a gearbox which were operating, at a slow motion, a metallic agitator of a specially designed plade type shape . Preliminary experiments proved that one to three revolutions per minute rotation of the plades gave the best condition of settling. Water was added to the settling vessel through an opening in the upper section of the vessel by a centrifugal pump put on the zero level of the plant. The installation was mechanically designed so as to eliminate vibrations by using elastic absorbers. A manually operated on-off gate valve controls the outlet of the settled 
solids, as well as the whole contents of the Perspex settler. Results showed an increase in the settling rates over laboratory results, and, of course, a decrease of the settling periods accompanied by highly arranged features of particles coagulation. This is now under experimental examination in our engineering laboratories in the Faculty of Engineering at Minia University for both fine and coarse particles as well as for dilute and concentrated suspensions.

\section{Conclusions and Recommendations}

Dross, as a waste of melting aluminum metal, is up-till now, considered as an enemy to the environment being a pollutant, which is also a source of losing some entrained aluminum metal .

This waste is now either landfilled, or being sold at very low prices. Trials to regain aluminum losses from drosses are now advancing well by our metallurgical collegues [12-15] The present investigation transformed the aluminum content of that dross to aluminum sulfate which has a coagulating activity and is used industrially as alum for helping the sedimentation and settling processes.

In its liquid form the PADT may be used by changing its concentration to that one adequate for a certain process; or it may be transformed to solid forms. This procedure will give higher economic value for the drosses obtained, increasing the income of the aluminum producing factories besides its envronmented impact ; The present investigation is a investigation , which needs further steps to ameliorate the production means and qualities. Thus, it can be said that the aluminum dross has no longer been an aluminum waste, but it may become one of its important by-products.

\section{Acknowledgement}

The auther appreciates well the efforts made by collegue Prof. Dr. Taha Farrag, by Prof. Dr. Jamal Abu-Elmajd (the first elected dean of the faculty ) and by our chemical engineering technicians in the faculty of engineering El-Minia University , Egypt 


\section{$\underline{\text { References }}$}

[1] Private contact with the research center at the Egyptalum company at Nag Hammadi , Feb. 2011.

[2] R.D. Peterson, and L. Newton, Review of aluminum dross processing, light metals , the minerals , metals and materials society, 2002.

[3] J.Y. Hwang and $\mathrm{x}, \mathrm{xu}, \mathrm{z}, \mathrm{Hwang}$, Recovery of metals from aluminum dross and salt cake , J.of minerals and materials characterization and engineering, Vol.5, No.1, (2006) pp 4762 .

[4] E.Petavratzi and S. Wilson, Residues from aluminum dross recycling in cement, a case study, mirobre, (mineral industry research organization) Nov.2007.

[5] American Encyclopedia (G.Enterprises, New York), Vol.1(1988)p.640,.

[6] W.L. Faith, D.B. Keyes and R.L clark, Industrial chemicals, John Wiley and sons, New York, 1972.

[7] L.D., Benefield, J.F. Judkins and B.L. Weand, Process chemistry for water and waste water treatment, printice-Hall, Englewood cliffs , NJ, 1982.

[8]J.N.,Stephenson, Pulp and Paper Manufacture , Mc Graw -Hill,New York. Vol.(1951), Vol.II.

[9] G.T., Austin, shreve's chemical process industries , Mc Graw-Hill, New York,1985.

[10] J.M.Coulson .and J.F Richardson. Chemical Engineering , V.2, $3^{\text {rd }}$ ed.,ch.3, (1978) pp.176-225,.

[11] M.A. Mohamed, M.E. Kassim, and E.A.El-Katatny, Optimization of the extraction of aluminum sulfate and ammonium aluminum sulfate alums from aluminum dross tailings , J.Mater.Res.,V.13, (1998) No.4.

[12] P. LeBrun, , C. Krautlein , G.Rembach Pouly,P.,De vries and J.Luyten, Removal of intermetallic particles for the purification of aluminum alloys, proceeding of the light metal conference, Minerals , Metals and Materials Society(2007), PP.657-667,.

[13] J. Mukhopadhyay, Y.V. Ramana and Singh Upendra , Extraction of value added products from aluminum dross material to achieve zero waste, Light metals (2004), the minerals, metals and materials society .

[14] D.J. Roth, and P.G. schirk, cold cleaning and concentrating of non-ferrous dross, proc,. Of $4^{\text {th }}$ intern. Symp.on recycling of metals and engineering materials, (2000) P.1105, Oct.22-25.

[15] J.W. Pickens, Assuring the benefits of aluminum recycling, proc. of $4^{\text {th }}$ intern. symp. on recycling metals and engineering materials, (2000) P.1195,Oct.22-25. 


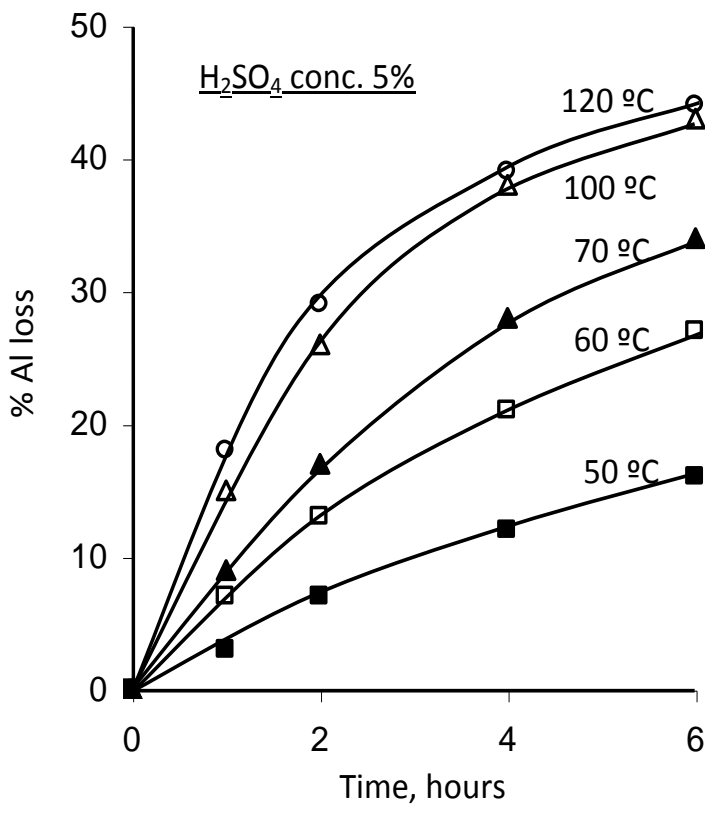

Fig. (1): Effect of temperature on aluminum loss.

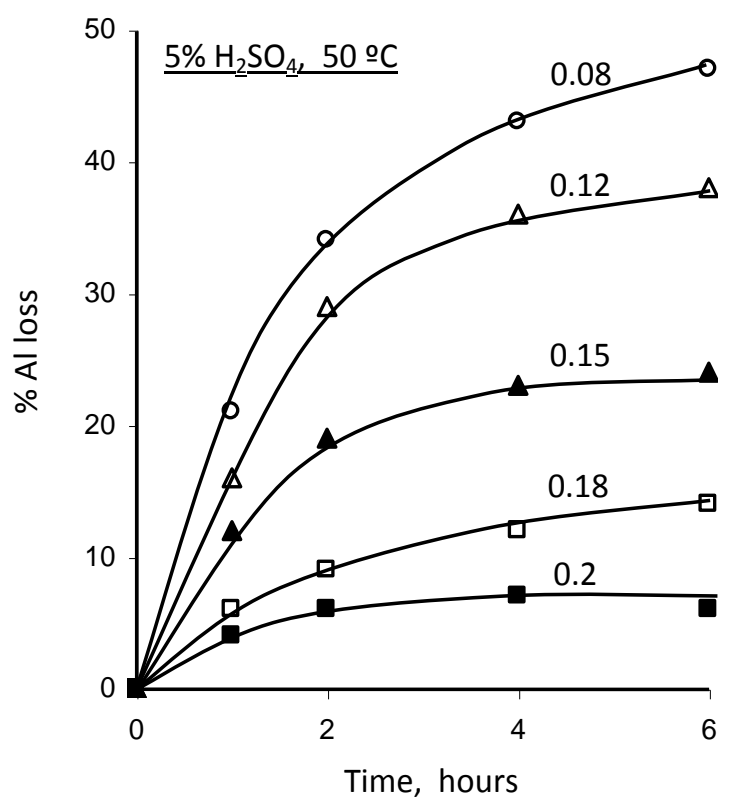

Fig. (3): Effect of the solid/liquid ratio on aluminum loss.

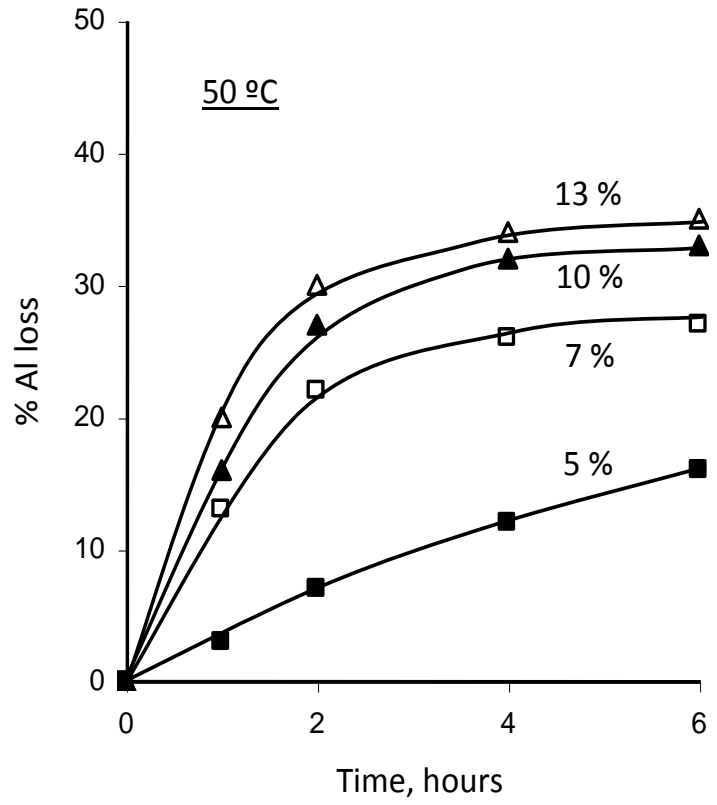

Fig. (2): Effect of sulfuric acid concentration on aluminum loss.

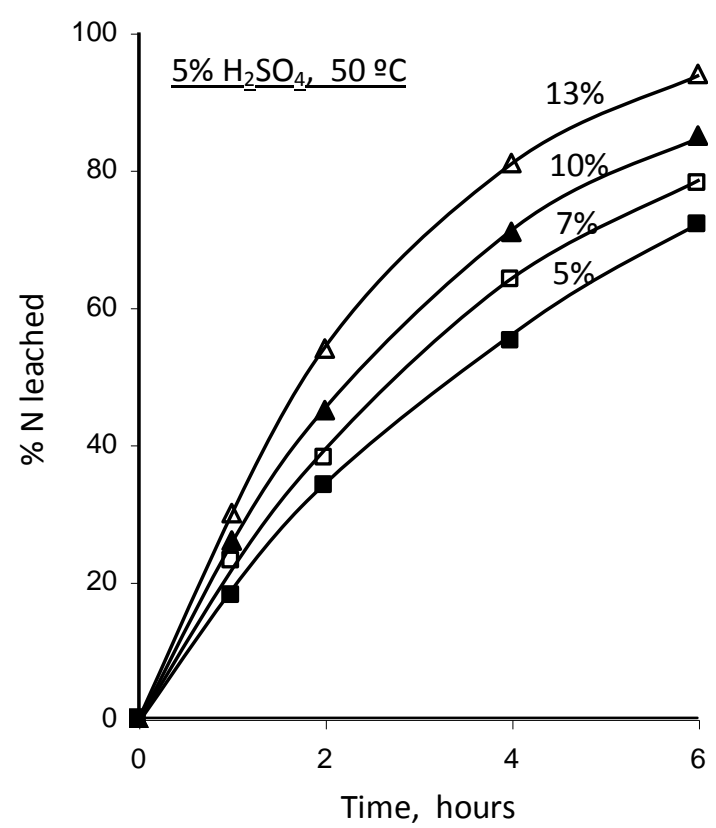

Fig. (4): Effect of sulfuric acid concentration on the percent nitrogen leached. 


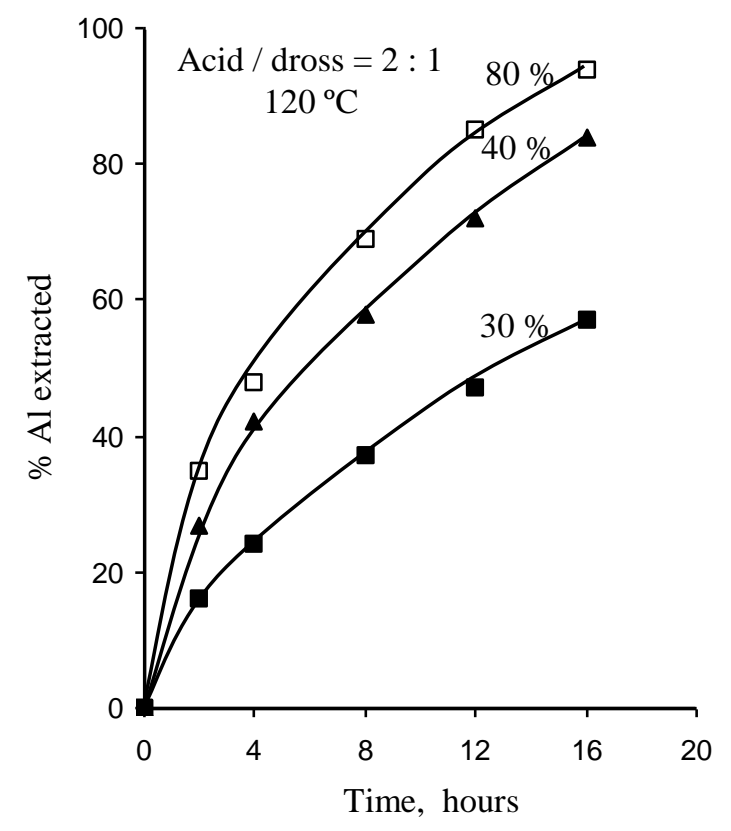

Fig. (5): Effect of acid concentration on percent aluminum extracted.

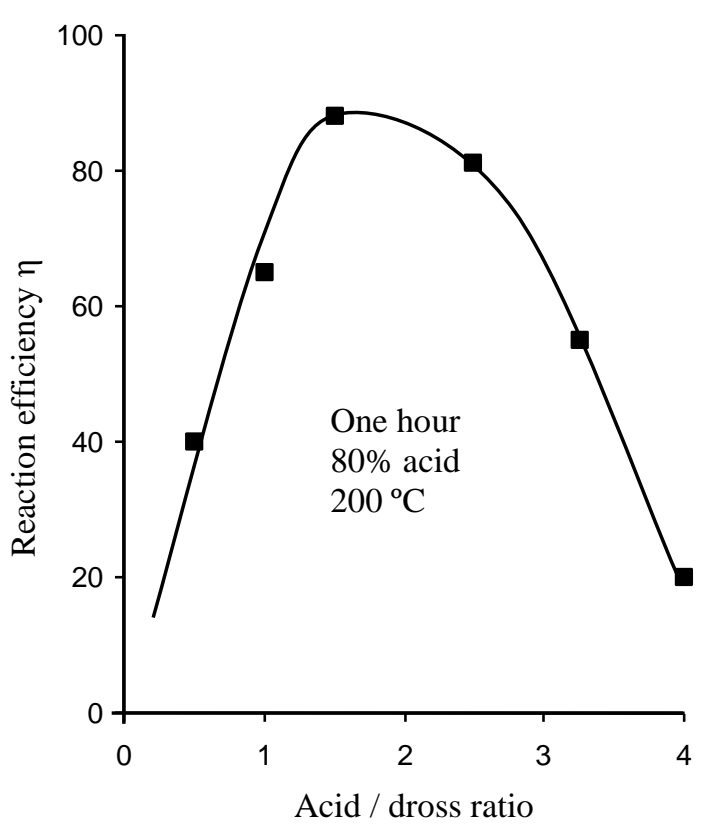

Fig. (7): Reaction efficiency at $200{ }^{\circ} \mathrm{C}$ for different acid ratios. $\eta=($ Al extracted $/$ calculated $\mathrm{Al})$

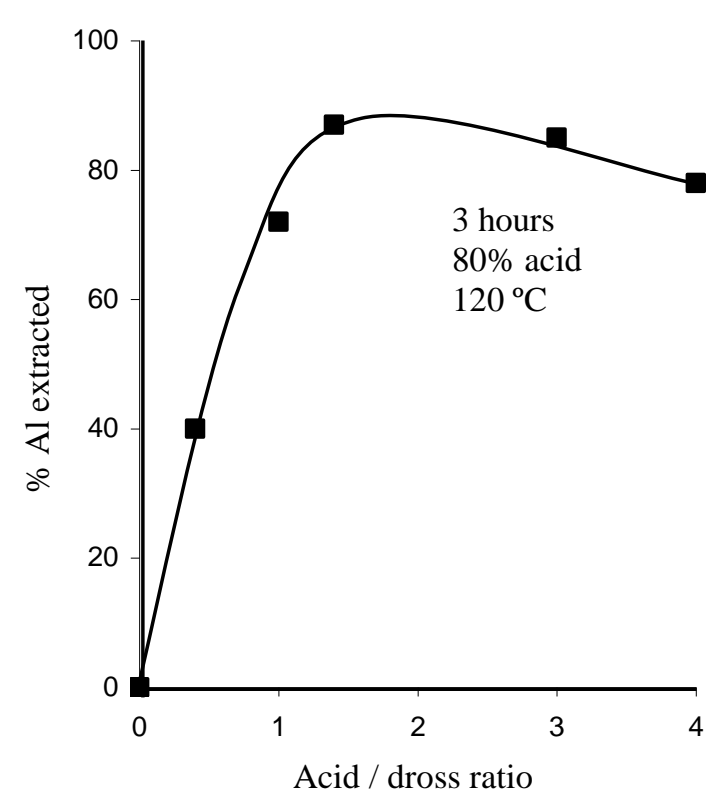

Fig. (6): Extracted aluminum at different acid ratios.

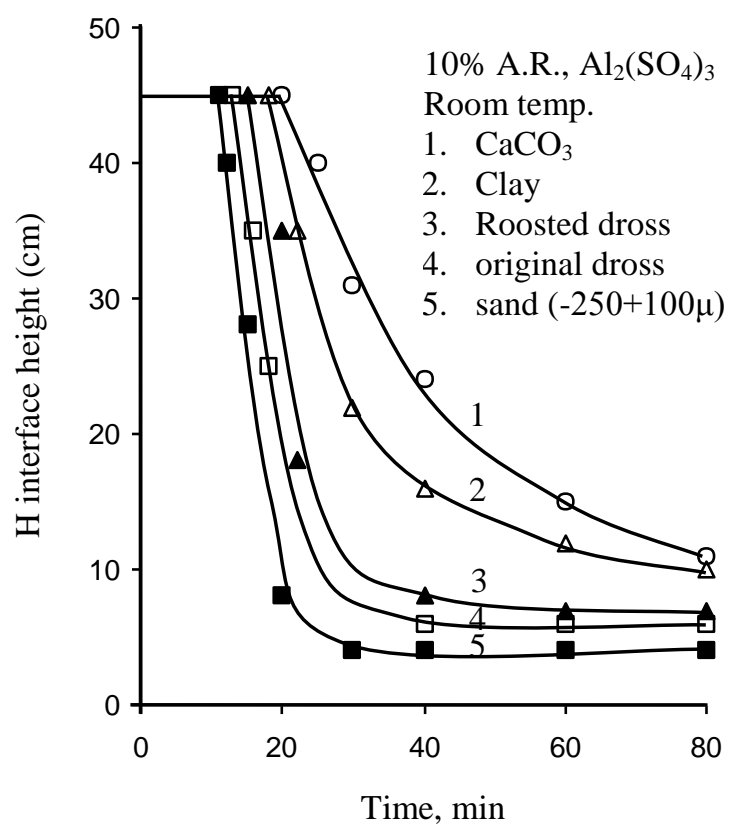

Fig. (8): Effect of $\mathrm{Al}_{2}\left(\mathrm{SO}_{4}\right)_{3}$ on the sedimentation of some relative materials of $0.3 \%$ concentration. 


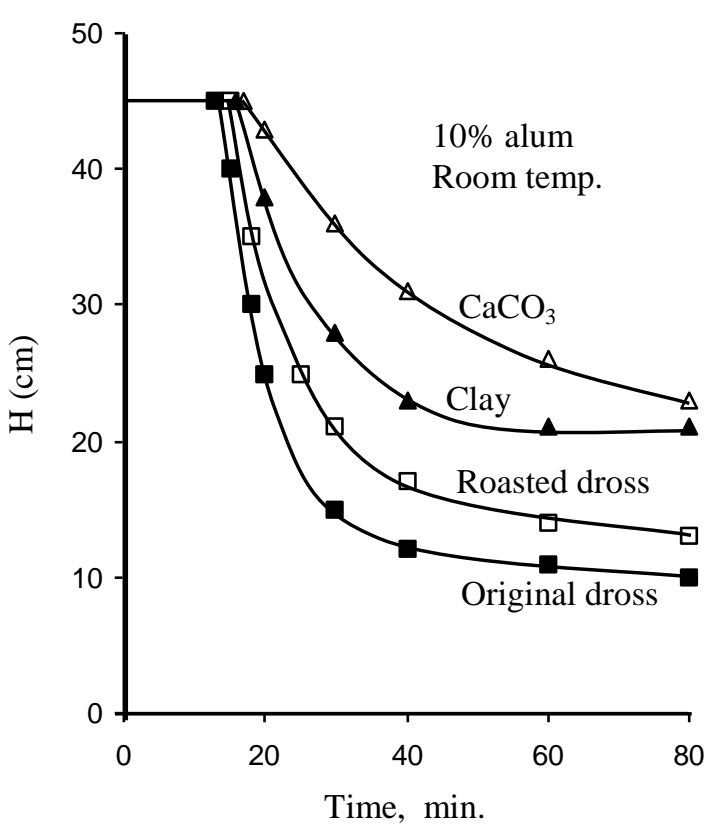

Fig. (9): Effect of commertial alum on sementation features

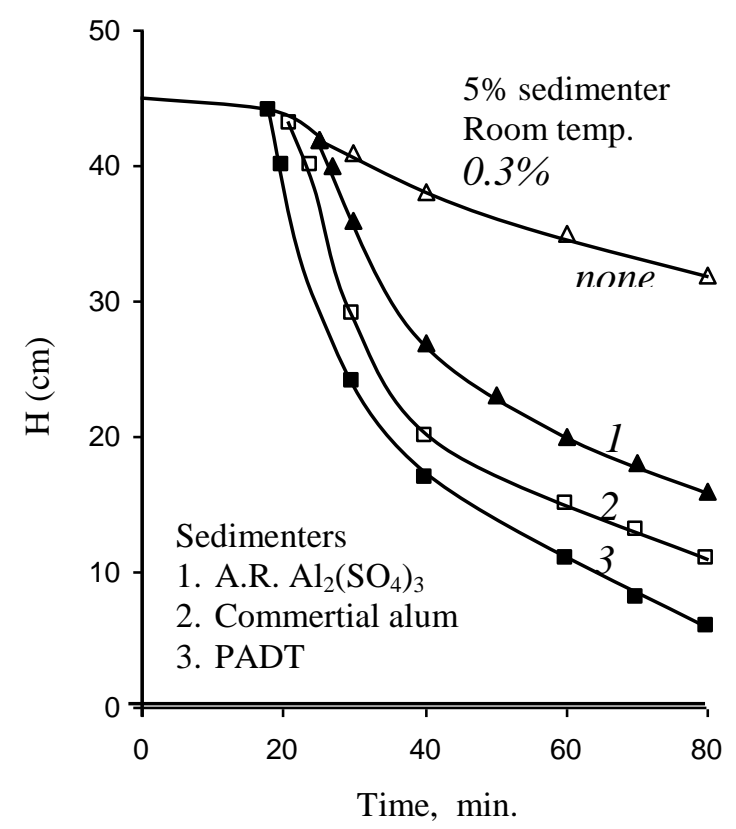

Fig. (11): Relative efficiencies of sedimenting elements.

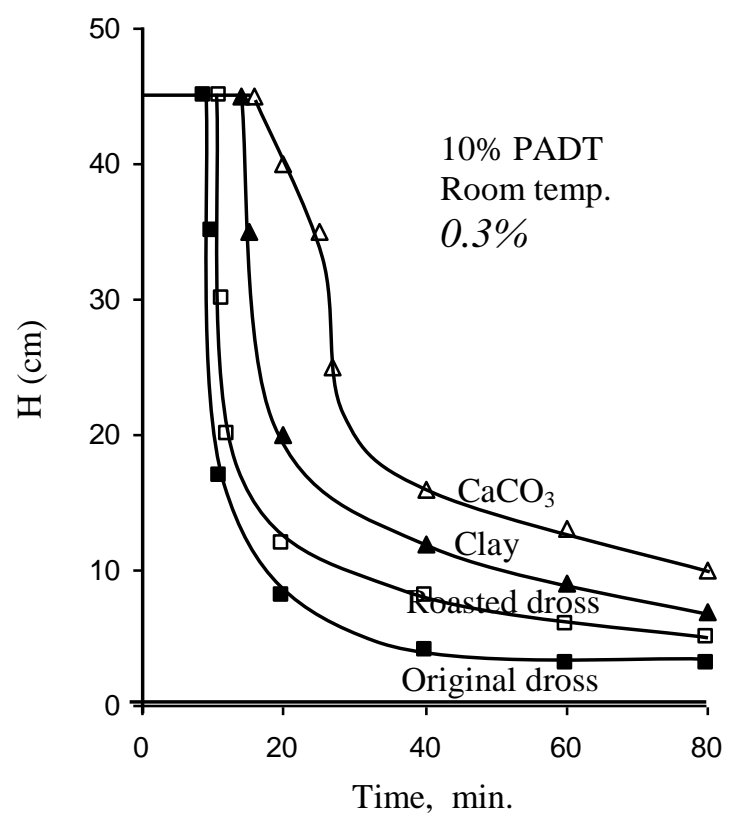

Fig. (10): Effect of the prepared dross alum on sementation features

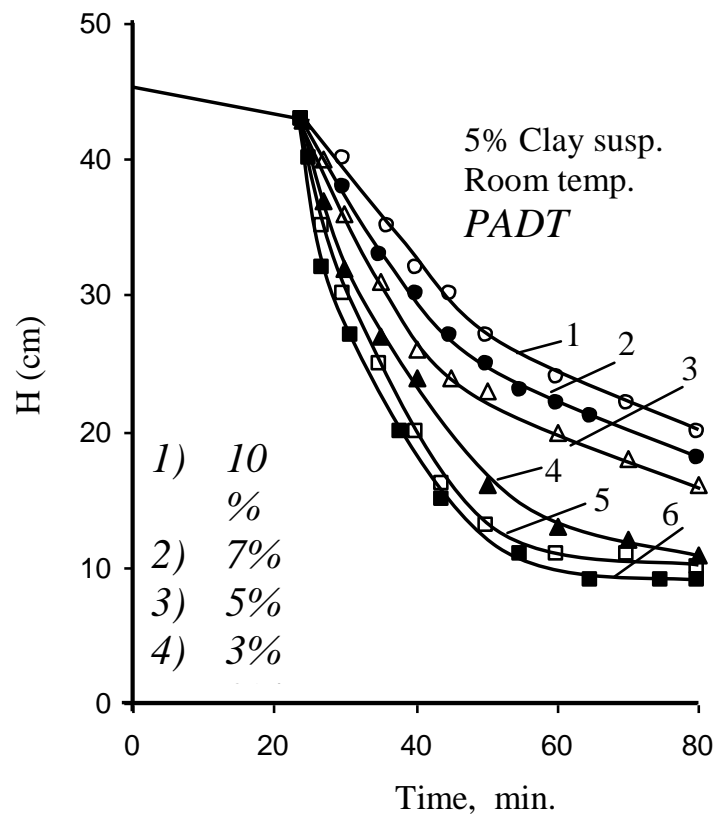

Fig. (12): Sedimentation behaviour of PADT at different concentrations. 


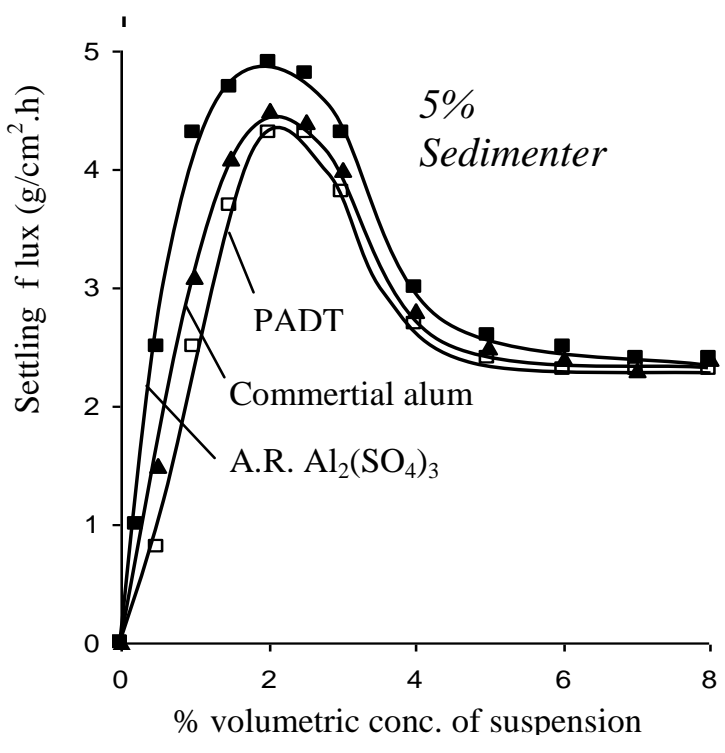

Fig. (13): Settling flux of clay suspensions using various sedimenters.

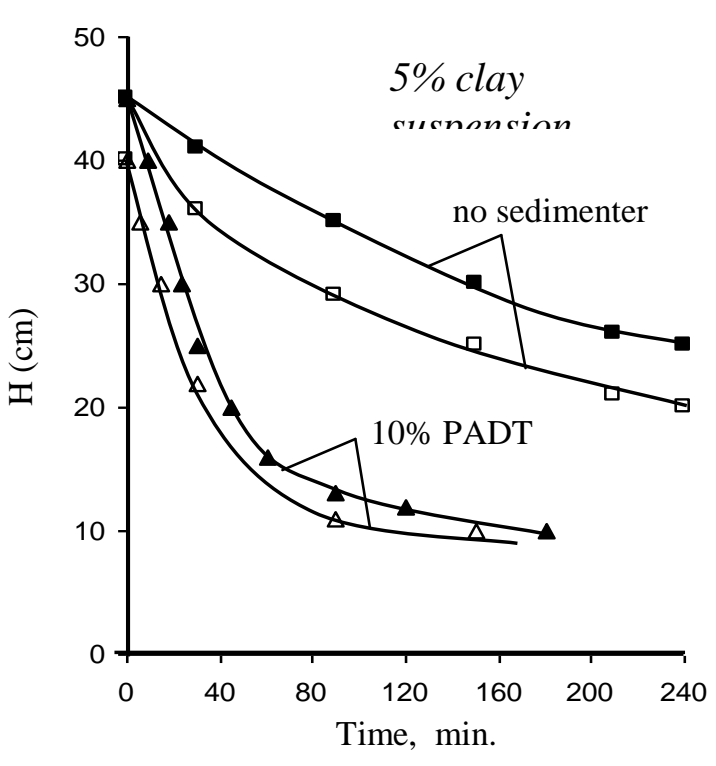

Fig. (14): Effect of starting sedimentation height on rate of sedimentation .

1. Motor

2. Gear box

3. Agitator

4. Prespex settler

5. Movable cover

6. Metallic installation

7. Vibration absorbers

8. Suspension

9. Agitator guide

10. Ladder

11. On-off valve

12. Water tank

13. Centrifugal pump

14. Water inlet

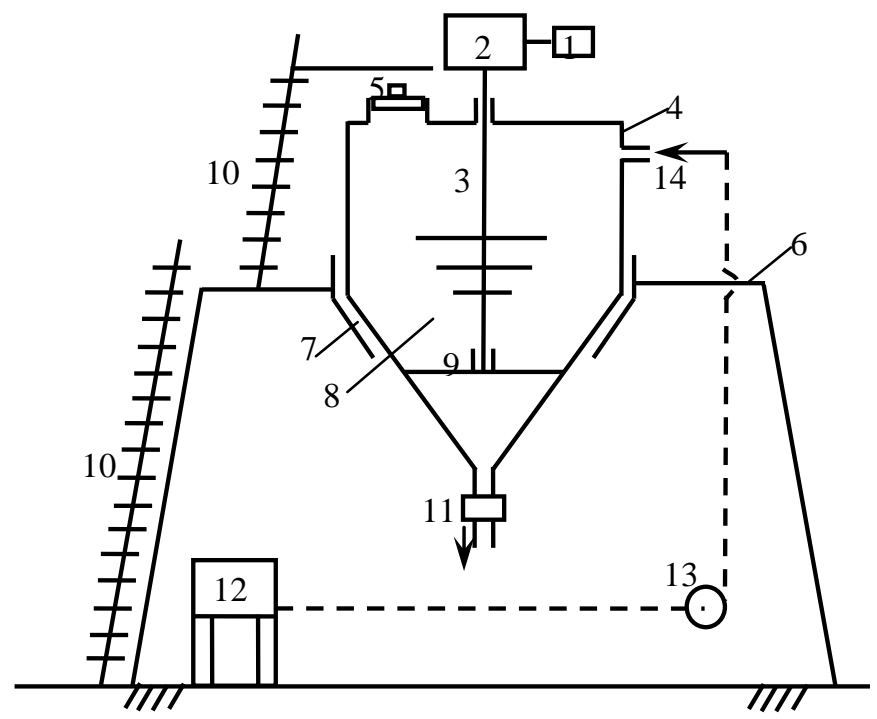

Fig. (15): Prespex Semi-Pilot Batch Settler (Schematic representation). 